\title{
Assessing the Endogeneity of OCA Conditions in EMU
}

\begin{tabular}{|c|c|}
\hline Journal: & The Manchester School \\
\hline Manuscript ID: & MSH-2011-0185 \\
\hline Manuscript Type: & Supplement Issue \\
\hline $\begin{array}{r}\text { Date Submitted by the } \\
\text { Author: }\end{array}$ & 07-Nov-2011 \\
\hline Complete List of Authors: & $\begin{array}{l}\text { Vieira, Carlos; Universidade de Évora, CEFAGE-UE and Departamento } \\
\text { de Economia } \\
\text { Vieira, Isabel; Universidade de Évora, CEFAGE-UE and Departamento } \\
\text { de Economia }\end{array}$ \\
\hline Specialty Area: & $\begin{array}{l}\text { F15 - Economic Integration }<\text { F1 - Trade }<\text { F - International } \\
\text { Economics }\end{array}$ \\
\hline
\end{tabular}




\title{
Assessing the Endogeneity of OCA Conditions in EMU
}

\author{
Carlos Vieira and Isabel Vieira \\ CEFAGE-UÉ, Universidade de Évora, Portugal
}

\begin{abstract}
:
The academic and political discussion about which countries met the conditions for joining EMU was decisively influenced by the Frankel and Rose (1997) hypothesis concerning endogenous OCA properties. The answer to their question "Is EMU more justifiable ex post than ex ante?" was a definite yes in their ex ante analysis. Our ex post examination of the euro's first decade, however suggests that the hypothesis does not hold for some countries. This paper utilizes panel data estimation techniques to compute OCA indices that help assess the OCA endogeneity hypothesis and signal current external and fiscal imbalances.
\end{abstract}

Key words: optimum currency areas, OCA index, monetary union JEL Classification: F15, F36 


\section{1 - Introduction}

The hypothesis of endogenous optimum currency areas (OCA), suggesting that economic and monetary integration are self reinforcing processes, had an important role in shaping the European economic and monetary union (EMU). It provided academic support to the political will to strengthen the level of integration in the European Union (EU) and may have influenced peripheral countries' decisions to attempt an early entry into EMU, in the hope that the much needed convergence of their economies would be easier and quicker under a common currency. Ten years into EMU, the dire economic and social conditions currently evidenced by those countries, which in some cases have cast doubt on their capacity to continue in EMU, suggest that, at least in their case, the expected improvement of OCA properties may have failed to materialize or was insufficient to allow smooth adjustment following a crisis.

In this study, we assess the endogeneity of the OCA conditions for the first group of EMU members plus Greece. We use the OCA index proposed by Bayoumi and Eichengreen (1997) which assesses compliance with OCA properties and is obtained with an out-of-sample approach based on a two-step procedure. The relationship between bilateral exchange-rate variability and a set of traditional OCA conditions is first estimated using panel data techniques and a data set covering 21 members and nonmembers of EMU during the two pre-euro decades. In a second step, the OCA index is derived from the estimated equation and extrapolated to obtain the index values for the post-euro period. The computed indices for each EMU member in the last three decades are the basis for our assessment of the behavior of OCA properties before and after the introduction of the euro. 
Our analysis adds to the empirical OCA literature in three ways. Firstly, we employ a more complete and updated dataset and more robust panel-data estimation techniques to compute the index proposed by Bayoumi and Eichengreen (1997). Secondly, we project the estimated indices to the post-euro decade in order to assess the OCA endogeneity hypothesis. Thirdly, we consider whether the OCA indices could have been a good predictor of the difficulties now emerging in the fragile member states.

This work may be of interest for current EMU candidates trying to determine the best timing to adopt the common currency and whether such move would speed up their catching up process. It may also be useful for countries in other continents, already involved in less rigorous economic integration schemes but ultimately aiming at monetary integration.

Frankel and Rose $(1997,1998)$ developed ex ante assessments of the OCA endogeneity hypothesis and concluded that the European monetary union would be more justifiable ex post. Their studies uncovered the convergence effects of economic integration amongst EU members but could not cover a period of time long enough to expose the trends set in motion by the euro. Comparing the decades preceding the introduction of the common currency with the one that followed, we ask whether, as suggested by ex ante analyses, EMU is indeed a self-fulfilling prophecy.

We find out that, in general, the OCA properties have improved for most analyzed countries, either members or non-members of EMU, but the EMU periphery has not performed as well as predicted by the endogeneity hypothesis. The distance separating peripheral and core economies before the introduction of the euro remains practically unchanged after ten years of adopting the common currency. We also obtain positive cross-country correlations between the values of the OCA index before EMU and the 
fiscal and current account deficits in 2009, suggesting that the index can be a useful indicator of future troubles in less-prepared economies.

The rest of the paper is organized as follows: section two briefly surveys some theoretical and empirical aspects of OCA theory and their impact on the development of the European monetary union project; section three describes the data and the variables used in the statistical analysis and estimates the model; section four computes the OCA indices for the pre- and post-euro periods and examines the hypothesis that the OCA characteristics are endogenous to EMU; section five compares the values of the index at the time of accession with the current fiscal and external imbalances displayed by the European countries; section six concludes and discusses some policy implications

\section{2- EMU and the OCA theory}

The idea of monetary integration was in the minds of the architects of the European integration project almost from its inception in the late 1950s. However, the road to monetary union proved to be long, because EMU, though politically desirable, involved exceptional processes with uncertain outcomes. Its members give up much of their economic autonomy while retaining political independence. To date, no other multinational venture has attempted to reach such high levels of economic and monetary integration without fiscal and/or political centralization. Consequently, no real case scenarios could be studied to anticipate the consequences of EMU membership or to decide which countries should join, postpone, or opt-out.

In order to guarantee the sustainability of the single-currency project, candidates were required to meet a set of nominal conditions, the so-called Maastricht criteria, before 
being allowed to join. ${ }^{1}$ However, regardless of the specificity and mandatory status of such requirements, the selection of countries to enter EMU was more political than technical.

The originality of the EMU project stimulated a large political and academic debate about its reasonability and the main advantages and costs for participating countries. Many discussions were grounded on OCA theory which, overall, suggests that monetary union is more beneficial for open economies much involved in mutual trade and displaying synchronized business cycles, high levels of labor mobility or price and wages flexibility, and financial and fiscal integration. ${ }^{2}$ Since monetary integration entails the loss of autonomy over domestic monetary policy and of exchange-rate flexibility, OCA conditions should either substitute for them or render them less necessary.

Despite its popularity, recognition of OCA theory as a suitable tool to evaluate monetary integration in general and EMU in particular has varied over time. It was one of the most prominent references up to the 1970s, lost predominance in the 1980s and regained it from the 1990s onward. The works of Frankel and Rose $(1997,1998)$ were especially important to the revival of the theory. They formulated and provided ex ante empirical support for the endogeneity hypothesis, saying that, though a set of candidates did not constitute an OCA before EMU, they would become one as a consequence of entering it, rendering monetary integration more justifiable ex post.

\footnotetext{
${ }^{1}$ The Maastricht criteria were nominal requirements of price stability, fiscal prudence, successful European Monetary System membership and interest rate convergence.

${ }^{2}$ A recent comprehensive survey of the more relevant theoretical and empirical OCA developments may be found in Dellas and Tavlas (2009).
} 
The OCA endogeneity argument may have influenced decisions to enter and allow entry to EMU. ${ }^{3}$ In the second half of the 1990s, especially in the southern EU countries, domestic economic policies were greatly restricted by the short-term objective of fulfilling the nominal convergence criteria. Economic structures in the South were rather different from those of the EU core, but the alternative of postponing entry until attaining a higher degree of real convergence was dismissed, perhaps due to political fear of being an EMU outcast, but due also to the leap of faith that the catching up would be quicker under monetary integration. ${ }^{4}$

Early studies considered the OCA conditions as a static conditio sine qua non for adopting the single currency. However, dynamic effects are relevant in analyses of monetary integration and are at the core of two paradigms, anticipating opposing scenarios for the future of EMU: the OCA endogeneity hypothesis due to Frankel and Rose (1997, 1998), and the specialization hypothesis proposed by Krugman (1991, 1993).

Frankel and Rose viewed the OCA conditions as 'jointly endogenous', rejecting static evaluations of individual OCA properties. Focusing on the extent of trade and on the similarity of shocks and business cycles inside a currency area, the authors predicted that savings in transactions costs following the adoption of the single currency would intensify trade between EMU countries which would, in turn, synchronize business cycles.

\footnotetext{
3 The European Parliament also added to the spreading of the idea that economic conditions would improve under EMU, by concluding, in a report published in 1998, that 'many of the asymmetries might be removed by the coordination within EMU of economic policies, ... and by the fact of monetary union itself' (our underlining, in European Parliament, 1998, pp. 5 - 6).

${ }^{4}$ The impact of political agendas on the design of the road to monetary integration in Europe is analysed, for instance, in Feldstein (1997).
} 


\footnotetext{
${ }^{5}$ Analyses of African and Asian countries may be found, respectively, in Bangaké (2008) and in Achsani and Partisiwi (2010). Bénassy-Quéré and Lahrèche-Révil (2000), Cincibuch and Vávra (2001), Schweickert (2001), Sadeh (2005) or Horvàth (2007) focused in the CEECs.
}

Krugman, on the other hand, considered the possibility of more intense trade relations promoting less, rather than more, synchronized business cycles. If, following the reduction in trading costs, attempts to take advantage of increasing returns to scale motivated the relocation of firms and changes in regional industrial structures, more trade would lead to a higher level of productive specialization. In such a case, the probability of asymmetric shocks would increase and the synchronization of business cycles would decline.

In this study, we examine indirectly whether more specialization, or more synchronization, has been promoted by EMU. We do so by contrasting the values of the OCA index before and after the introduction of the common currency. This index, proposed by Bayoumi and Eichengreen (1997), has also been utilized in studies identifying the determinants of exchange-rate variability (as in Horváth, 2005) and in analyses assessing the eligibility of specific countries or groups of countries for monetary integration. Some of the latter focused in African or Asian economies but most analyzed Central and Eastern European countries (CEECs), producing mixed conclusions regarding their capacity to join the single currency. ${ }^{5}$

The absence of consensus in empirical assessments of the CEECs' readiness for EMU enhances the utility of the lessons that can be drawn from the current experience of countries such as Greece, Ireland, Portugal or Spain. It is thus interesting to determine whether participation in EMU appears to have improved individual countries' OCA qualities and if convergence has been facilitated by the dynamics of economic and monetary integration. 
In order to address these questions, we estimate the model proposed by Bayoumi and Eichengreen (1997) and then utilize the estimates to construct individual countries' OCA indices. Extending the period of time assessed by those authors but utilizing similar variables for the same set of countries, we test the robustness of the original approach and its current value.

\section{3 - The OCA determinants of exchange rate variability}

In the estimating equation below, the variability of bilateral exchange rates is dependent on a series of explanatory variables that encapsulate traditional OCA desiderata: the asymmetry of business cycles between the two countries, dissimilarity in the composition of their exports, their bilateral openness ratio and their average economic dimension:

$$
\operatorname{sder}_{i j t}=\beta_{0}+\beta_{1} s d y_{i j t}+\beta_{2} \operatorname{dissim}_{i j t}+\beta_{3} \text { btrade }_{i j t}+\beta_{4} \operatorname{size}_{i j t}+e_{i j t},
$$

where the dependent variable $s_{d e}{ }_{i j t}$ is the standard deviation over a ten-year period of the yearly log-variations in the bilateral nominal exchange rate between countries $i$ and $j, s d y_{i j t}$ is the standard deviation of the difference in the log of real output growth between countries $i$ and $j$, dissim $i j t$ is the sum of the absolute differences in the relative share of each of eleven chain categories of merchandise trade in each pair of countries, ${ }^{6}$ btrade $_{i j t}$ is the mean of the ratio of bilateral exports to domestic GDP in both countries, size $_{i j t}$ is the mean of the two countries' log of GDP measured in US dollars, and $e_{i j t}$ is the

\footnotetext{
${ }^{6}$ Bayoumi and Eichengreen (1997) considered only three categories: manufactured goods, food and minerals. We chose the more detailed and informative classification from Chelem and used its eleven categories of products by chains: energy, food agriculture, textiles, wood paper, chemicals, iron and steel, non ferrous, machinery, vehicles, electrical and electronic.
} 
stochastic error term. All variables are measured as averages over a ten-year period. The original hypothesis is that countries meeting the OCA conditions to a greater degree face more stable exchange rates. Therefore all coefficients are expected to be positive except for $\beta_{3}$ (as bilateral exchange rates are apt to be less volatile if the other country is an important trade partner).

Data on bilateral nominal exchange rates were collected from the IMF's International Financial Statistics; GDP at constant prices in domestic currency comes from the OECD statistical database; all the trade-related variables and current GDP in US dollars were computed from the CEPII-Chelem database.

The equation above was estimated for the pre-euro period using panel data comprising 420 annual observations, covering the two ten-year periods prior to EMU, 1979-88 and 1989-98, and including 21 OECD countries: eleven EMU countries (Austria, Belgium, Finland, France, Germany, Greece, Ireland, Italy, the Netherlands, Portugal and Spain), three non-EMU, EU members (Denmark, Sweden and the UK), and seven non-EU countries (Australia, Canada, Japan, New Zealand, Norway, Switzerland and the US). A dummy variable for the period 1979-88 (d88) was also included to account for the higher average exchange-rate variability in the 1980s. Using panel data allows, among other benefits, more degrees of freedom and control for state- and time-invariant variables, producing more reliable parameter estimates.

The estimation with a random-effects model (the Hausman test allowed using the more efficient model with consistent results) produced the following results (standard errors are reported in parentheses, the overall R-squared is 0.462): 


$$
\begin{aligned}
& s_{d e r_{i j t}}=-0.253+1.646 s d y_{i j t}+0.023 \text { dissim }_{i j t}-0.864 \text { btrade }_{i j t}+0.015 \text { size }_{i j t}+0.024 d 88_{i j t} \\
& \begin{array}{lllll}
(.028) & (.167) \quad(.006) & (.121)
\end{array}
\end{aligned}
$$

All coefficients are statistically significant at the one per cent confidence level and display the expected signs. The results suggest that the standard OCA factors help to explain the dynamics of bilateral exchange-rate variability, confirming the previous findings in Bayoumi and Eichengreen (1997), ${ }^{7}$ although using a different methodology, a wider time frame, and a slightly different $\operatorname{dissim}_{i j t}$ variable. In order to check the stability of the coefficients over time, seventeen consecutive cross-section estimates have been performed for ten-year periods between 1973 and 1998. They display largely stable coefficients. Only the coefficient on $s d y_{i j t}$, the proxy for asymmetric shocks, is much lower, albeit still significant, during the first half of the 1980s. This probably reflects the relatively faster convergence dynamics of business cycles observable in the data for that period.

\section{4 - The OCA indices}

Like Bayoumi and Eichengreen (1997), we use our estimated equation to compute an index that compares each EU country's OCA characteristics relatively to a reference country. While those authors, and all later previously cited studies, calculated the index with the objective of ascertaining the readiness of EU countries to join EMU by the end of the 1990s, we will compare the pre- and post-EMU values of the index to assess the Frankel and Rose (1998) hypothesis that the OCA conditions are endogenous and to associate the index with the current financial distress faced by some EMU members.

\footnotetext{
${ }^{7}$ Later updated in Horváth (2007), who added some other factors to the OCA variables, removed Greece from the sample and estimated the equation by the generalized method of moments, obtaining similar results albeit a non-significant dissim variable.
} 
The index in Table 1 is computed for the relationship between Germany, traditionally regarded as the EU's anchor country, and every other European country in the sample. It covers three consecutive periods, 1979/88, 1989/98 and the post-euro decade 1999/08. The index corresponds to the fitted value for exchange-rate variability using the point estimates of the parameters obtained above and extrapolating for the post-euro period, when no exchange-rate variability can occur within the euro area. The index is thus a weighted sum of each country's various OCA conditions, taking the equation above as deterministic. The smaller the value of the index, the more do the two countries approximate an OCA.

Table 1: Rankings of OCA indices for the European countries

\begin{tabular}{llllll}
\hline \multicolumn{2}{c}{1988} & \multicolumn{2}{c}{1998} & \multicolumn{2}{c}{2008} \\
\hline Belgium & 0.01907 & Austria & 0.01222 & Belgium & 0.00203 \\
Austria & 0.03289 & Belgium & 0.01389 & Austria & 0.00442 \\
Netherlands & 0.03397 & Netherlands & 0.04473 & Netherlands & 0.03639 \\
Finland & 0.05709 & Denmark & 0.05862 & Finland & 0.03839 \\
Switzerland & 0.06175 & Switzerland & 0.06297 & Switzerland & 0.04141 \\
Sweden & 0.06563 & France & 0.06985 & Denmark & 0.04362 \\
Italy & 0.06628 & Italy & 0.07278 & France & 0.06301 \\
France & 0.06906 & Portugal & 0.07718 & Sweden & 0.06636 \\
Denmark & 0.06933 & Spain & 0.08147 & Portugal & 0.06916 \\
Ireland & 0.07656 & Ireland & 0.08668 & Italy & 0.07240 \\
Greece & 0.08878 & Sweden & 0.08858 & Spain & 0.07815 \\
UK & 0.09321 & Greece & 0.09773 & UK & 0.07984 \\
Norway & 0.09440 & Norway & 0.10100 & Norway & 0.08500 \\
Spain & 0.09857 & UK & 0.10263 & Greece & 0.09982 \\
Portugal & 0.10178 & Finland & 0.10827 & Ireland & 0.10616 \\
\hline
\end{tabular}

Note: The index is computed using the regression estimates obtained above for the bilateral relationships with Germany.

The countries are arranged in ascending order of the value of the index in each period (which is in descending order of their OCA ranking). The table reveals that Austria, Belgium and the Netherlands remain in the top three, Switzerland is fifth, the two oil 
producers, Norway and the UK, always rank next to each other near the bottom of the table, and the other countries change slightly their relative positions between periods. These relative positions for the pre-euro rankings are quite similar to those obtained by Bayoumi and Eichengreen (1997) or, using a different approach, by Kim and Chow (2003).

The evolution of the index and the changes in the rankings may be more perceptible in Figures 1 and 2, where all points below the 45-degree line from the origin indicate a declining index and thus that the country improved its classification in terms of the OCA factors between the two periods. Pursuant to OCA theory, a country closer to the origin is more prepared to deal with the constraints of a single currency.

Figures 1 and 2: Change in the OCA indices, 1988-1998 and 1998-2008
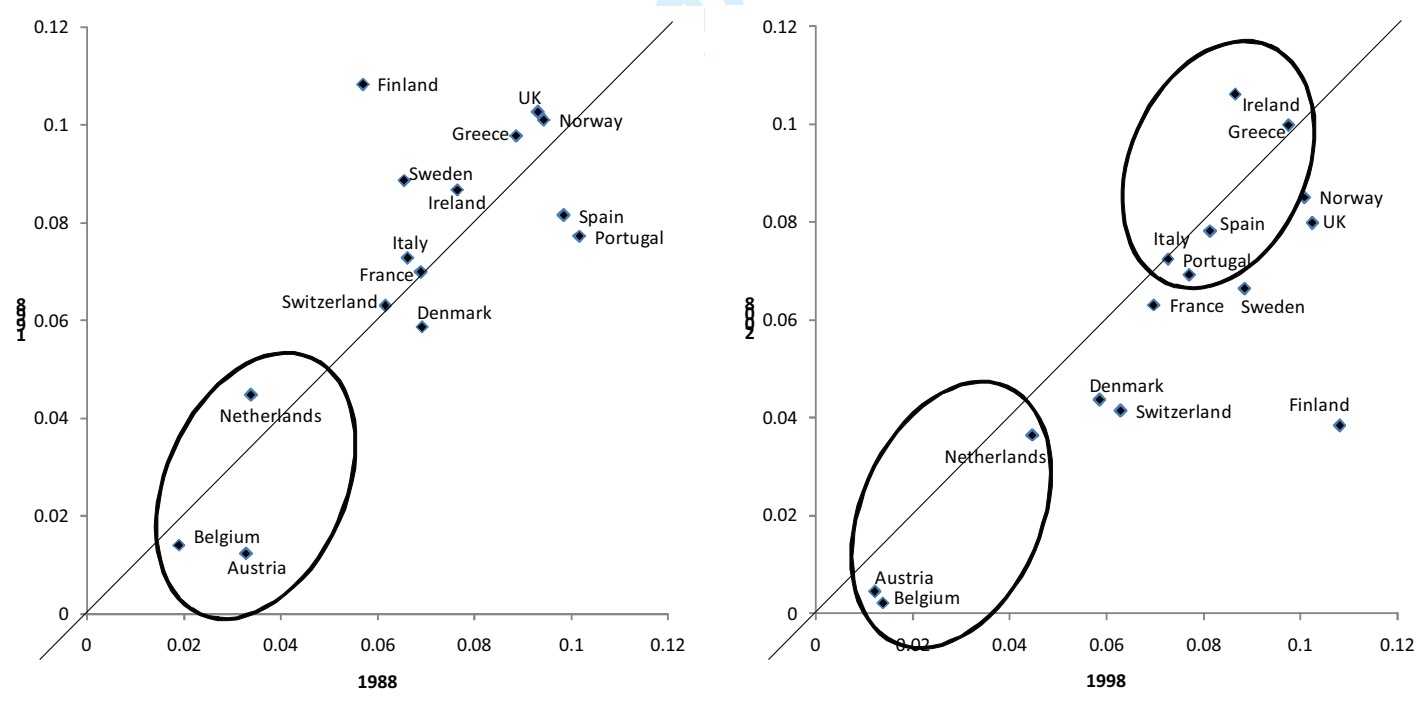

Austria, Belgium and the Netherlands are the countries most closely tied to Germany's economy. Portugal and Spain were at the bottom of the table in the period 1979/88 but, following accession to the EU in 1986, greatly improved the quantitative measure of their OCA attributes, and these were two of the few countries that improved their OCA 
index between the 1980s and the 1990s. Finland dips to the bottom of the table, due to severe economic and banking crises in the early 1990s. Apart from Finland, the bottomranked five countries in the period immediately preceding EMU are, according to the OCA index, those that have not been able or chose not to adopt the euro or to be a member of the EU (UK, Norway, Greece and Sweden). Above this group are ranked those countries that were immediately admitted to EMU but are currently, with Greece, experiencing the most difficulty coping with membership (Ireland, Spain, Portugal and Italy). The OCA index could thus have served as an indicator of the difficulties to come, suggesting that these countries should have postponed entry.

The right-hand figure, which compares the immediate pre- and post-euro periods, shows that all the latter countries (plus Greece, which joined the euro in 2001) have fallen in their OCA index ranking, notably Ireland and Greece, the only two countries in the sample actually increasing their index values between 1998 and 2008. In fact, most countries display lower values in the post-euro period, apparently confirming the endogeneity hypothesis of Frankel and Rose (1998). The same progress also occurs, however, in non-EMU countries, suggesting that common, more global, factors must be considered.

\section{5 - The OCA index and the fiscal and external imbalances}

The ability of the OCA index to signal the conditions for joining a monetary union, and thus to anticipate problems due to the loss of the traditional domestic policy instruments, can be further supported by comparing the index for each country with its current fiscal and external positions. 
In the aftermath of the global financial and economic crisis, some euro area countries, mostly Mediterranean, face major economic problems that may even threaten their place in the euro area or, in the extreme, the long-run survival of the European single currency. The main problem for these countries is their substantial loss of competitiveness against their northern euro partners and third countries, reflected in the build-up of major fiscal and external imbalances (see, for instance, Blanchard, 2007, Geppert and Stephan, 2008, or Shelburne 2010).

Figure 3 illustrates the connection between each country's OCA index value for 1998 and its government's fiscal imbalances in 2009. It reveals a clear cross-country correlation between those variables.

Figure 3: General government deficits in 2009 and the 1998 OCA index

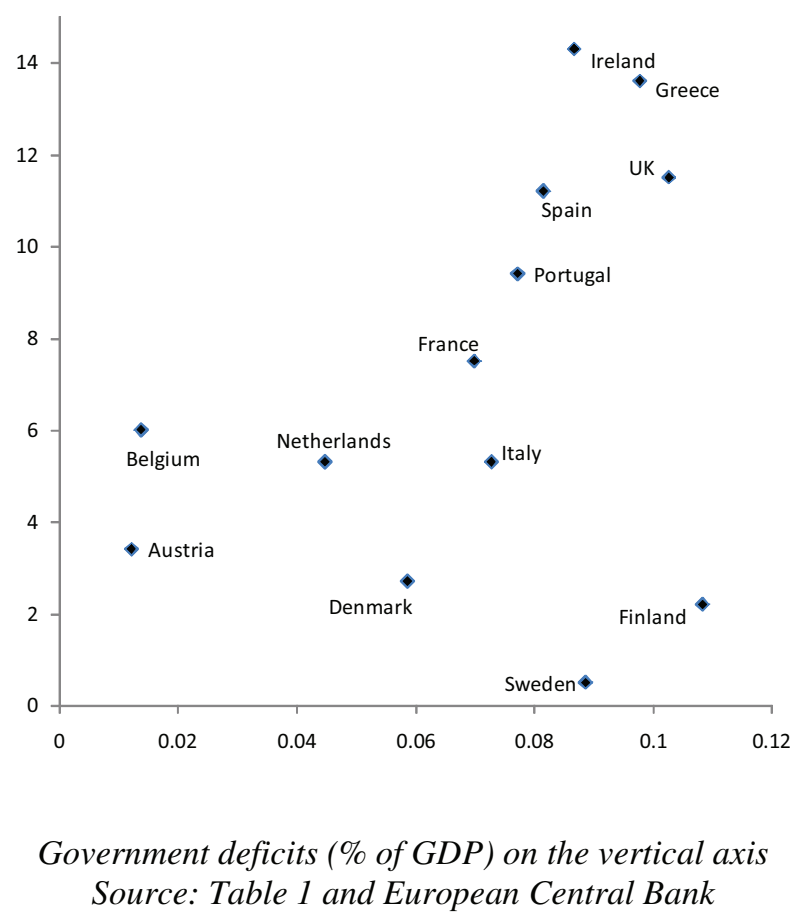

This correlation was absent in the pre-euro period, as was noted by Bayoumi and Eichengreen (1997) when comparing the OCA index with the Maastricht criteria, 
Figure 4: Current account deficits in 2009 and the 1998 OCA index

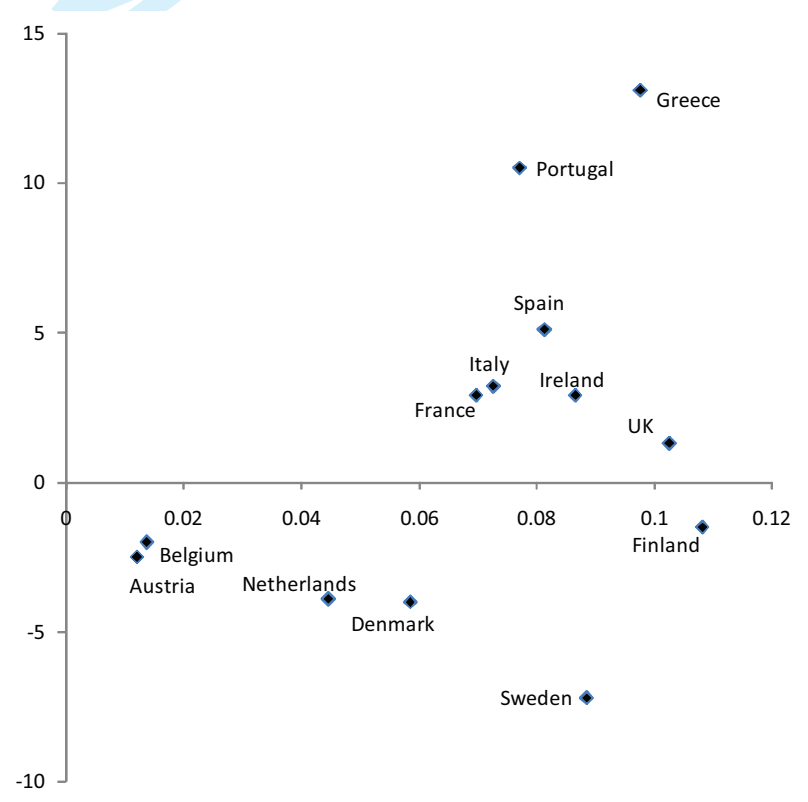

Current account deficits (\% of GDP) on the vertical axis Source: Table 1 and European Central Bank

Many, mostly politicians, had expected that being in the euro, with its guarantee of macroeconomic stability and lower interest rates, would help to increase competitiveness levels (see, for instance European Parliament, 1998). The endogeneity hypothesis may have helped fuel this expectation. Reality, however, has shown that competitiveness has fallen in some of the less prepared members, now that devaluation is no longer an option. As suggested by Christodoulakis (2009), the access to cheaper 
capital provided by EMU membership has aggravated pre-existing current-account deficits in peripheral countries. Unlike the core EMU members, the periphery has attracted relatively more investment in the non-tradable sector (the housing boom being a good example), which resulted in a progressive deterioration of the trade balance.

\section{6 - Conclusions}

Despite the wishful thinking that EMU would generate its own success, the prospect of monetary integration in Europe was always controversial. When eleven EU countries entered the third stage of EMU in 1999, proving wrong those who predicted that such a project would never see the light of day, optimists celebrated but critics waited for developments to confirm their belief that the euro was 'a bad idea'. They did not have to wait more than a decade for the first serious problems. Following the 2007 financial crisis, the aggravated structural problems encountered by some euro zone members raised doubts about the survival of the euro and also about the validity of the OCA endogeneity hypothesis.

The endogeneity hypothesis has been subject to various assessments. Many have anticipated a priori that EMU would be closer to an OCA after its completion, but only ex post tests can determine whether this has in fact been the case, and only if the hypothesis is confirmed by all participating countries irrespective of specific start-up characteristics.

Ten years into EMU, we have developed an evaluation of OCA endogenous properties to ascertain whether the assumption that may have played an important part in the shaping of the European monetary union has been validated with the passage of time. 
Utilizing the OCA index first proposed by Bayoumi and Eichengreen (1997), we have compared individual countries' compliance with selected OCA conditions before and after the adoption of the euro. We conclude that OCA properties have improved in the last decade for practically all analyzed countries, either members or non-members of EMU, and thus that the improvement cannot be attributed solely to increased monetary integration. The more peripheral EMU countries actually displayed stronger signs of convergence during the decade preceding the adoption of the common currency than during the one that followed. Therefore, the much expected quicker convergence within EMU did not materialize, or the level attained so far was insufficient to allow the smooth adjustment of those economies in the aftermath of the global financial crisis.

Our estimates indicate that EMU itself did not improve the OCA characteristics of all participants, failing especially in cases where confirmation of that expectation was most critical. In fact, while the verification of the OCA endogeneity hypothesis would require decreasing indices after EMU, Greece and Ireland increased their values in the first decade of membership, while Portugal and Spain continued to display much larger values than the countries with the best performance.

Our analysis also suggests that the OCA index could have been a better indicator of countries' readiness to join the single currency than were the Maastricht criteria, as the latter were not able to identify the ill-prepared countries. The recent troubles of some euro area members make this clear. Our results should thus be pondered when deciding to allow new members into the euro area before they have attained a sufficient level of convergence, particularly in terms of business-cycle synchronization and trade linkages.

\section{References:}


Achsani, N and Partisiwi, T (2010) Testing the feasibility of ASEAN+3 single currency comparing optimum currency area and clustering approach, International Research Journal of Finance and Economics, Issue 37, pp. 79-84.

Bangaké, C (2008) Exchange rate volatility and optimum currency area: evidence from Africa, Economics Bulletin, 6(12), pp. 1-10.

Bayoumi, T and Eichengreen, B (1997) Ever closer to heaven? An optimum-currencyarea index for European countries, European Economic Review, Volume 41, Issues 3-5, pp. 761-770.

Blanchard, O (2007) Current account deficits in rich countries, NBER Working Paper Number 12925.

Bénassy-Quéré, A and Lahrèche-Révil, A (2000) The Euro as a monetary anchor in the CEECs, Open Economies Review, Volume 11, Number 4, pp. 303-321.

Cincibuch, M and Vávra, D (2001) Toward the European Monetary Union: a need for exchange rate flexibility? Eastern European Economics, Volume 39, Number 6, pp. 2364.

Christodoulakis, N (2009), Ten years of EMU: convergence, divergence and new policy priorities, National Institute Economic Review, Volume 208, Number 1, pp. 86-100.

Dellas, H and Tavlas, G (2009) An optimum-currency-area odyssey, Journal of International Money and Finance, vol. 28(7), pp. 1117-1137.

European Parliament (1998) Adjustment to asymmetric shocks, Directorate-General for Research Working Paper, Economic Affairs Series, ECON 104.

Feldstein, M (1997) The political economy of the European Economic and Monetary Union: political sources of an economic liability, Journal of Economic Perspectives, Volume 11, Issue 4, pp. 3-22. 
Frankel, J and Rose, A (1997) Is EMU more justifiable ex post than ex ante?, European Economic Review, Volume 41, Issues 3-5, pp. 753-760.

Frankel, J and Rose, A (1998) The endogeneity of the optimum currency area criteria, Economic Journal, Volume 108, Issue 449, pp. 1009-1025.

Geppert, K and Stephan, A (2008) Regional disparities in the European Union: convergence and agglomeration, Papers in Regional Science, Volume 87, Issue 2, pp. 193-217.

Horváth, R (2005) Exchange rate variability, pressures and optimum currency area criteria: some empirical evidence from the 1990s, Applied Economics Letters, Volume 12, Issue 15, pp. 919-922.

Horváth, R (2007) Ready for Euro? Evidence on EU new member states, Applied Economics Letters, Volume 14, Issue 14, pp. 1083-1086.

Kim, Y and Chow, H (2003) Optimum currency area in Europe: an alternative assessment, Economics Letters, Volume 81, Issue 3, pp. 297-304.

Krugman, P (1991) Increasing returns and economic geography, Journal of Political Economy, Volume 99, Number 3, pp. 483-499.

Krugman, P (1993) Lessons of Massachusetts for EMU, in F Torres and F Giavazzi (Eds) Adjustment and Growth in the European Monetary Union, Cambridge University Press.

Sadeh, T (2005) Who can adjust to the euro?, The World Economy, Volume 28, Issue 11, pp. 1651-1678.

Schweickert, R (2001) Assessing the advantages of EMU-enlargement for the EU and the accession countries: a comparative indicator approach, Kiel Working Papers 1080. 
Shelburne, R (2010) Current account deficits in European emerging markets, UNECE Discussion Papers Series No. 2008.2.

\begin{abstract}
Acknowledgements
We thank Esmeralda and Joaquim Ramalho, Fernanda Peixe, Aurora Galego and José Caetano for valuable comments. The usual disclaimer applies. We gratefully acknowledge partial financial support from Fundação para a Ciência e Tecnologia (FCT), program FEDER/POCI 2010.
\end{abstract}

